\title{
HYDROTHERMAL AND SOLVOTHERMAL SYNTHESIS OF CERIUM-ZIRCONIUM OXIDES FOR CATALYST APPLICATIONS
}

\author{
Siti Machmudah ${ }^{1 *}$, Muhamad Risky Ceaser ${ }^{1}$, Muhammad Fareid Alwajdy ${ }^{1}$, Widiyastuti ${ }^{1}$, \\ Sugeng Winardi ${ }^{1}$, Wahyudiono ${ }^{2}$, Hideki Kanda ${ }^{2}$, Motonobu Goto ${ }^{2}$ \\ ${ }^{1}$ Department of Chemical Engineering, Institut Teknologi Sepuluh Nopember, Kampus ITS, Sukolilo, \\ Surabaya 60111, Indonesia \\ ${ }^{2}$ Department of Materials Process Engineering, Nagoya University, Furo-cho, Chikusa-ku, \\ Nagoya 464-8603, Japan
}

(Received: July 2018 / Revised: October 2018 / Accepted: April 2019)

\begin{abstract}
Cerium oxide $\left(\mathrm{CeO}_{2}\right)$ is a rare earth metal oxide that has high oxygen storage capacity at low temperature. In order to enhance this capacity, as well as its thermal stability, it is necessary to combine $\mathrm{CeO}_{2}$ with zirconium oxide $\left(\mathrm{ZrO}_{2}\right)$. This work focuses on the synthesis of ceriumzirconium oxides by hydrothermal and solvothermal treatment at low temperature to obtain ones suitable for catalyst applications. The possibility of the application of ceria-zirconia oxide to the delignification reaction was investigated. The experiments were conducted at a constant pressure of $5 \mathrm{MPa}$, constant temperature of $150^{\circ} \mathrm{C}$, and constant synthesis time of $2 \mathrm{~h}$, in an autoclave reactor made of SUS 316 with an internal volume of $100 \mathrm{~mL}$. Precursor was prepared from $\mathrm{Ce}\left(\mathrm{NO}_{3}\right)_{3}$ and $\mathrm{ZrO}\left(\mathrm{NO}_{3}\right)_{2}$ at $0.06 \mathrm{M}$ concentration, dissolved in various solvents. The solvents used were water, water/ethanol (70:30 vol/vol), and water/ethylene glycol (70:30 vol/vol). After hydrothermal and solvothermal synthesis, the colloid products were dried at $60^{\circ} \mathrm{C}$ for $6 \mathrm{~h}$ and then calcined at $500^{\circ} \mathrm{C}$ for $6 \mathrm{~h}$. The characterizations of the particle products were analyzed using SEM and XRD. Furthermore, these products were used for the hydrothermal delignification process of wood biomass. The addition of ceria-zirconia particles dramatically increased the percentage of lignin removal from rapeseed wood up to $97.58 \%$. Based on the results, ceria-zirconia oxide particles are effective for the pre-treatment of wood biomass in bio-refinery applications. Moreover, ceria-zirconia oxides may reduce the use of chemical compounds in the delignification process.
\end{abstract}

Keywords: Cerium oxide; Delignification; Hydrothermal; Solvothermal; Zirconium oxide

\section{INTRODUCTION}

Cerium oxide has a beneficial redox property, and therefore it is applied in reactions in many industries and at the lab scale as an eco-friendly redox catalyst; for example, in hydrogen production, water gas shift reactions, and automotive exhaust gas conversion. Recently, investigations have been conducted into the application of cerium oxide as an adsorbent for $\mathrm{CO}_{2}$ capture (Kusrini et al., 2018). Many catalytic reactions have employed cerium oxide at lower operating temperatures compared to other oxides, especially in reactions with oxygen as a reactant, due to its redox nature (Kwon et al., 2011). It is established that cerium has the capacity to change between two oxidation states, +3 and +4 that characterizes its redox property. Cerium keeps the oxygen in reserve in aerobic conditions and discharges it in anaerobic conditions in

\footnotetext{
*Corresponding author's email: machmudah@chem-eng.its.ac.id, Tel.+62-31-5946240, Fax. +62-31-5999282 Permalink/DOI: https://dx.doi.org/10.14716/ijtech.v10i3.2930
} 
order to gratify its stoichiometry. This characteristic is responsible for the oxygen storage capacity (OSC) property of cerium. However, pure cerium oxide has limitations in OSC and thermal stability due to the effect on its surface area at higher temperatures of the growth of nucleation and crystallites within the cerium pores (Lundberg et al., 2002).

Several attempts have been made to counter the restrictions of pure cerium oxide. Some rare earth metal oxides, such as lanthanum, yttrium, zirconia and silica, have been added to improve the OSC and thermal stability of cerium oxide by raising its pore parameters (Suda et al., 2001). It is well-known that the ionic conductivity of cerium oxide can be increased by the ion doping of the rare earth metal; moreover, cerium oxide catalytic activity can also be elevated by supplying lattice oxygen from the bulk to the surface (Zhou \& Gorte, 2008). Generally, cerium contains both $\mathrm{Ce}^{4+}$ and $\mathrm{Ce}^{3+}$ ions, which coexist in its lattice. The tetravalent cerium cation has a lower ionic radius of $0.97 \mathrm{~A}^{\circ}$ than the trivalent, which has a $1.14 \mathrm{~A}^{\circ}$ ionic radius. As a result, the close fluorite framework of the cerium is deformed. The tetravalent cations consolidate into the cerium lattice, the diffusivity capacity of oxygen can be changed, and the ion mobility inside the lattice will also be altered, with the establishment of subsidiary deformations. These deformations can be reduced by the generation of damage solid oxides structurally with smaller size tetravalent cations, such as $\mathrm{Zr}^{4+}$ (Reddy et al., 2007). Further, the combination of cerium with zirconium was formulated and the composite of $\mathrm{CeO}_{2}-\mathrm{ZrO}_{2}$ solid oxides exhibited appropriate thermal stability and redox capacity, together with certain characteristic features. The composite of $\mathrm{CeO}_{2}-\mathrm{ZrO}_{2}$ solid oxides with various compositions could improve the OSC (Machmudah et al., 2018).

In the last few years, cerium-zirconium oxides have become a key factor in many heterogeneous catalysis applications; moreover, they meet the zero-emission target of automotive exhaust gas. Cerium-zirconium oxides have been investigated in many areas of chemistry, such as the synthesis of butyl acetate from acetic acid and butanol (Yucai, 2006); the oxidation of landfill leachate (Aneggi et al., 2012); its application as a catalyst for the steam reforming of raw bioethanol (Palma et al., 2016); and as a catalyst for hydrogen production from methane reformation (Gil-Calvo et al., 2017). Delignification is the removal of lignin from woody tissue by natural enzymatic or chemical processes, such as oxidation reaction (Park et al., 2015). The delignification of biomass is lucrative and important in ethanol production from lignocellulosic biomass. In order to improve the removal of lignin from the biomass, it is necessary to find a simple process with a catalyst to enhance the oxidation reaction. From the literature review, it appears that the application of cerium-zirconium oxides in the delignification process has yet to be reported.

Cerium-zirconium oxides have been synthesized by the sol-gel process at ambient temperature (Rumruangwong \& Wongkasemjit, 2006). In this process, various chemicals need to be used for the preparation of the precursor, and a long synthesis time is needed. Numerous methods for cerium oxide synthesis have been reported, such as solution precipitation, thermal decomposition, ball milling, hydrothermal synthesis, solvothermal synthesis, spray pyrolysis, and thermal hydrolysis (Dhall \& Self, 2018). As with the sol-gel process, solution precipitation requires various chemicals and needs a long synthesis time. In ball milling, it is difficult to control particle size, while the other methods need high temperatures to form the particles.

In this work, the application of cerium-zirconium oxide particles in the delignification process is investigated. The cerium-zirconium oxides were synthesized by hydrothermal and solvothermal treatment, which are modest techniques for the synthesis of cerium-zirconium oxides particles. These methods allow the formation of particles in water or an organic solvent at temperatures above the boiling point of the solvent, as well as at pressures higher than the solvent vapor pressure. Synthesis was performed with water, ethanol/water $(70: 30 \mathrm{vol} / \mathrm{vol})$, and water/ethylene glycol $(70: 30 \mathrm{vol} / \mathrm{vol})$ as the solvent, at a temperature of $150^{\circ} \mathrm{C}$. The delignification process was 
conducted by hydrothermal treatment at $150^{\circ} \mathrm{C}$, with the addition of cerium-zirconium oxide particles synthesized by hydrothermal and solvothermal treatment. The effect of the addition of the cerium-zirconium particles on the lignin removal yield was also determined.

\section{METHODS}

\subsection{Materials}

All the chemicals used in this work were analytical grade and utilized without further refinement. $\mathrm{Ce}\left(\mathrm{NO}_{3}\right)_{3} \cdot 6 \mathrm{H}_{2} \mathrm{O}$ and $\mathrm{ZrO}\left(\mathrm{NO}_{3}\right)_{2}$ were purchased from Sigma Aldrich, Germany, and Wako, Japan, respectively. Ethanol and ethylene glycol used for solvent were provided by Merck, Germany, while the rapeseed wood for the biomass model substance was obtained from JChemical, Inc., Japan.

\subsection{Cerium-Zirconium Oxides Synthesis}

Cerium-zirconium oxide particles were synthesized by hydrothermal and solvothermal treatment in a batch autoclave reactor. The precursor was prepared from $\mathrm{Ce}\left(\mathrm{NO}_{3}\right)_{3} .6 \mathrm{H}_{2} \mathrm{O}$ (Sigma Aldrich, Germany) and $\mathrm{ZrO}\left(\mathrm{NO}_{3}\right)_{2}$ (Wako, Japan). Water, ethanol/water (70:30 vol/vol), and ethylene glycol/water $(70: 30 \mathrm{vol} / \mathrm{vol})$ were used as solvents. In order to change the pressure inside the reactor, the solvent was loaded into the reactor at $70 \%$ and $90 \%$ volume of reactor (reactor volume is $100 \mathrm{~mL}$ ). The pressure inside the reactor corresponded to 3 and 5 bar for $70 \%$ and $90 \%$ volume of loaded solvent, respectively. The synthesis method was similar to our previous work (Machmudah et al., 2018). Cerium nitrate and zirconium oxynitrate solutions were dissolved individually in the solvent at a concentration of $0.06 \mathrm{M}$, and combined at a ratio of $1: 1(\mathrm{vol} / \mathrm{vol})$. The precursor solution was loaded into a $100 \mathrm{~mL}$ Teflon beaker, and then inserted into the autoclave reactor made of SUS 316. Synthesis was conducted at a temperature of $150^{\circ} \mathrm{C}$ for $2 \mathrm{~h}$ in an electric furnace (Linn High Therm GmbH, model VMK 1600, Germany). After cooling the reactor in an ice batch, the precipitated solid was dried at $100^{\circ} \mathrm{C}$ for $24 \mathrm{~h}$ in an oven (Memmert UN 55, Germany), and then calcined at $500^{\circ} \mathrm{C}$ for $6 \mathrm{~h}$ in an electric furnace to form crystalline oxide particles.

\subsection{Characterization of Cerium-Zirconium Oxide Particles}

The characterization of the cerium-zirconium oxide particles was analyzed by a Scanning Electron Microscope (JEOL JSM-6390LV) and X-Ray Diffraction (XRD) to determine their morphology and crystallinity, respectively. Prior to SEM analysis, a platinum coating was applied to the particles to modify the diameter reading at higher magnifications. The XRD spectrum was examined to ensure that the cerium-zirconium oxides were composed of a crystal structure after being synthesized by this treatment. The XRD measurement was made by a Rigaku RINT 2100/PC XRD machine (40 kV and $200 \mathrm{~mA}$ ) installed in an $\mathrm{h}-\mathrm{h}$ wide-angle goniometer and scintillation detector using radiation of $\mathrm{Cu} \mathrm{Ka}\left(\mathrm{k}=1.5406 \mathrm{~A}^{\circ}\right)$. Energy Dispersive X-ray spectroscopy (EDX) was used to determine the elements that composed the cerium-zirconium oxides particles.

\subsection{Delignification of Rapeseed Wood}

The delignification of the rapeseed wood was performed using hydrothermal treatment in a batch reactor at $150^{\circ} \mathrm{C}$. Rapeseed wood mass of $0.2 \mathrm{~g}$ and $0.04 \mathrm{~g}$ cerium-zirconium oxide particles were loaded into a $25 \mathrm{~mL}$ Teflon beaker. Water was added into the beaker up to $70 \%$ of its volume. Subsequently, the beaker was put into an autoclave reactor made of SUS 316. The reactor was located into an electric furnace (Linn High Therm GmbH, model VMK 1600, Germany) and the temperature increased rapidly to $150^{\circ} \mathrm{C}$. The delignification process was conducted for $1 \mathrm{~h}$. After cooling the reactor for $1 \mathrm{~h}$ in an ice batch, the solid residue was filtered using Whatman paper filter, and then dried at $60^{\circ} \mathrm{C}$ for $24 \mathrm{~h}$. This was characterized using an FT-IR spectrophotometer (Perkin-Elmer, Ltd., England) to observe the solid residue structure. The lignin removal was 
analysed using the SNI 0494-2006 method and calculated using Equation 1. A schematic flow diagram of the delignification process is shown in Figure 1.

$$
\text { Lignin Removal }(\%)=\frac{\text { lignin in rapeseed } \text { wood-lignin in solid residu }}{\text { lignin in rapeseed } \text { wood }} \times 100 \%
$$

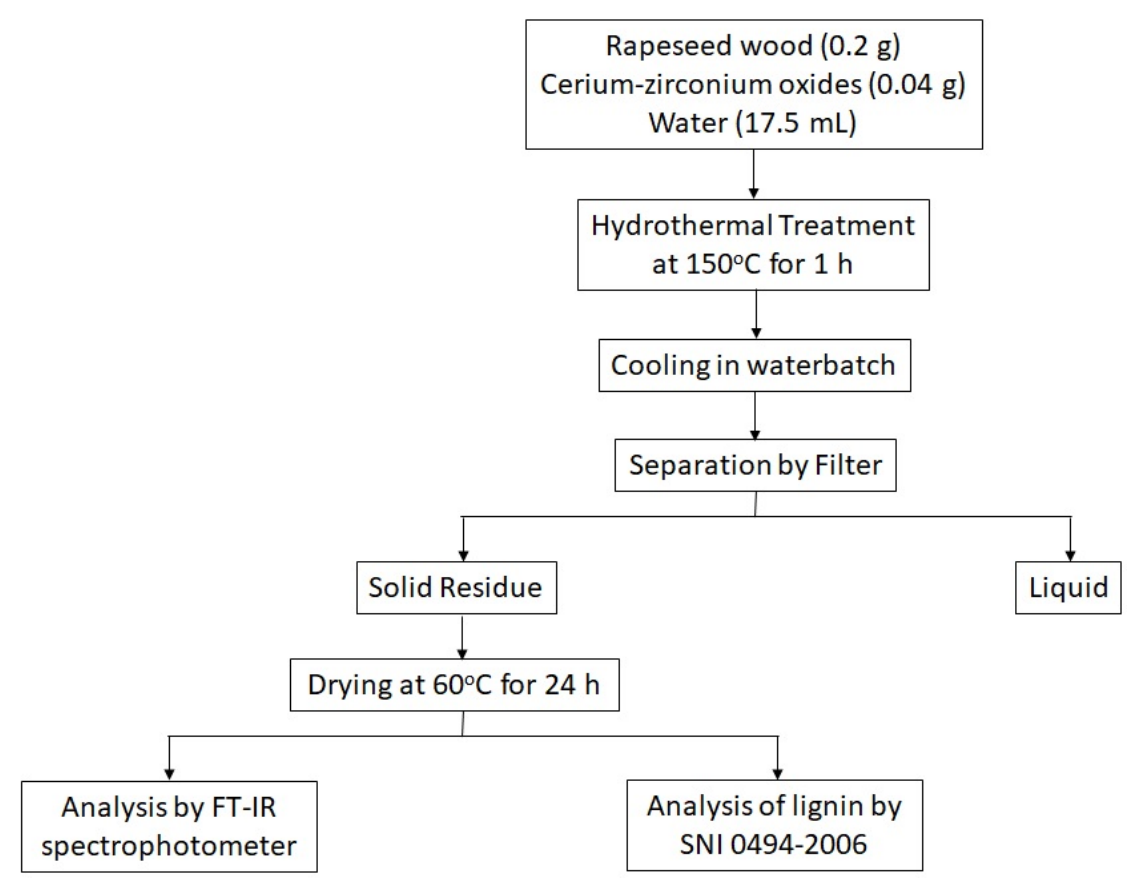

Figure 1 Schematic flow diagram of delignification process

\section{RESULTS AND DISCUSSION}

\subsection{Synthesis of Cerium-zirconium Oxide Particles}

Figure 2 shows the morphology of the cerium-zirconium oxide particles synthesized at a temperature of $150^{\circ} \mathrm{C}$, pressures of 3 and 5 bar for various water solvents, ethanol/water (70:30 $\mathrm{v} / \mathrm{v})$, and ethylene glycol/water $(70: 30 \mathrm{v} / \mathrm{v})$. The particles mostly consisted of cerium-zirconium oxides comprising small spherical particles with a size of less than $50 \mathrm{~nm}$, assembled to form plate-like shaped particles. The particles synthesized with water as solvent were assembled to form a solid plate-like shape with a large size and smooth surface morphology at high pressure ( 5 bar); on the other hand, smaller particles were formed at 3 bar. As in the case with water as the solvent, the increasing pressure caused increasing particle size with a porous morphology for synthesis using ethanol-water and ethylene glycol-water mixes as the solvent. Using the ethylene glycol/water mix, the particle pores became larger due to the higher dielectric constant of ethylene glycol. At high pressure, the ion products and dielectric constant of the solvent increased, resulting in the increase in particle growth. Furthermore, the particles tended to agglomerate and increase the size. Moreover, the agglomerated spherical particles produced by the ethylene glycol/water mix contained a large number of pores. From these results, it can be concluded that solvent type had a great affect on particle morphology, as demonstrated by the physical properties of the organic solvent, such as dielectric constant and conductivity. Both properties had a marked affect on the reaction occurring during the solvothermal synthesis. Besides, the existence of chemicals in the solution, including water, in particle synthesis at high temperature could restrain the shape morphology and size of the particles produced (Kanie et al., 2014). To perform the particle size, the equivalent diameter of the particles was determined from the SEM images using Equation 2: 


$$
D_{e q}=\frac{2 l w}{l+w}
$$

where $l$ and $w$ are length and width, respectively. The equivalent diameter of the synthesized particles is listed in Table 1. In the hydrothermal synthesis, this diameter slightly increased with an increase in pressure from 3 to 5 bar. In the batch process, the increasing pressure resulted in increased growth and precipitation rate of the particles, resulting in the larger particle size. In contrast, the organic solvent decreased the equivalent diameter of the synthesized particles due to the increase in the dielectric constant of the solvent.

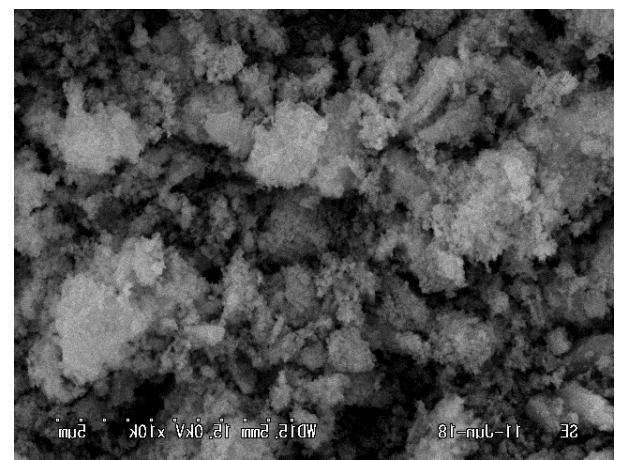

(a)

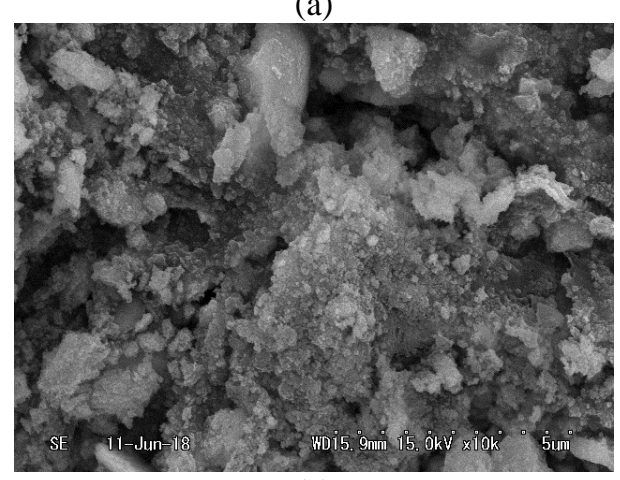

(c)

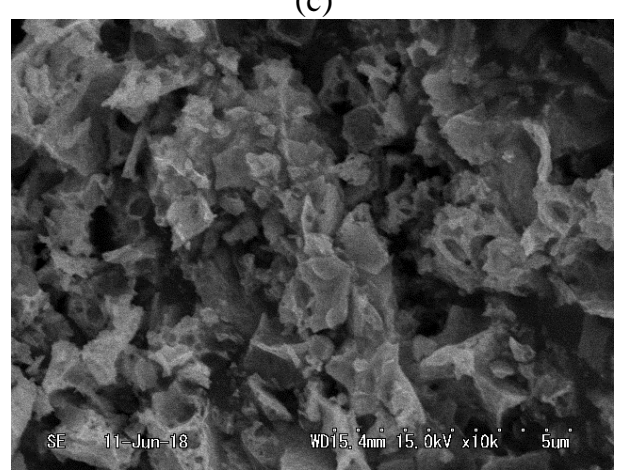

(e)

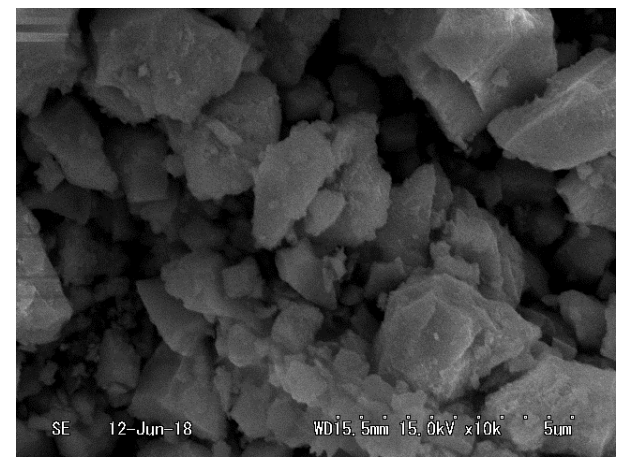

(b)

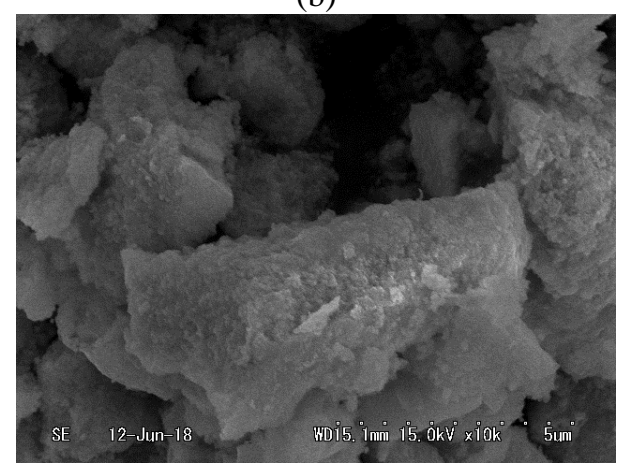

(d)

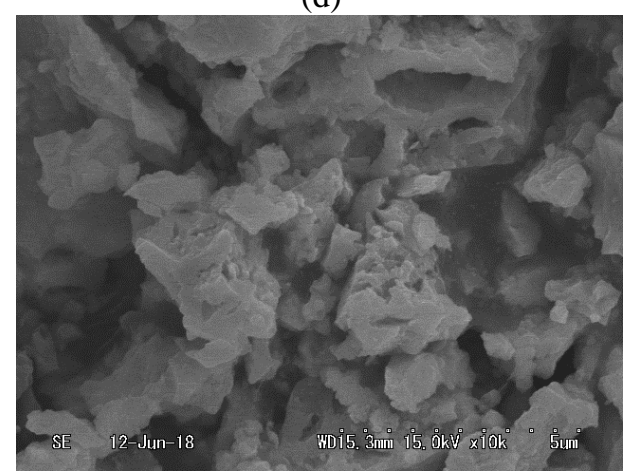

(f)

Figure 2 Images of synthesized particles by SEM at various pressures and solvents: (a) water, 3 bar; (b) water, $5 \mathrm{bar}$; (c) ethanol/water (70:30 v/v), 3 bar; (d) ethanol/water (70:30 v/v), $5 \mathrm{bar}$; (e) ethylene glycol/water (70:30 v/v), 3 bar; (f) ethylene glycol/water (70:30 v/v), 5 bar

The SEM EDX results for the synthesized cerium-zirconium oxide particles using the ethylene glycol/water $(70 / 30(\mathrm{v} / \mathrm{v}))$ solvent at 5 bar are shown in Figure 3. 
Table 1 Equivalent diameter of synthesized particles

\begin{tabular}{lcc}
\hline \multicolumn{1}{c}{ Solvent } & Pressure (bar) & Equivalent Diameter $(\mathrm{nm})$ \\
\hline Water & 3 & $821.9 \pm 20.5$ \\
Water & 5 & $1005.7 \pm 55.2$ \\
Ethanol-water $(70 / 30 \mathrm{v} / \mathrm{v})$ & 3 & $729.6 \pm 22.4$ \\
Ethanol-water $(70 / 30 \mathrm{v} / \mathrm{v})$ & 5 & $632.9 \pm 20.1$ \\
Ethylene glycol-water $(70 / 30 \mathrm{v} / \mathrm{v})$ & 3 & $856.4 \pm 21.2$ \\
Ethylene glycol-water $(70 / 30 \mathrm{v} / \mathrm{v})$ & 5 & $753.7 \pm 25.1$ \\
\hline
\end{tabular}

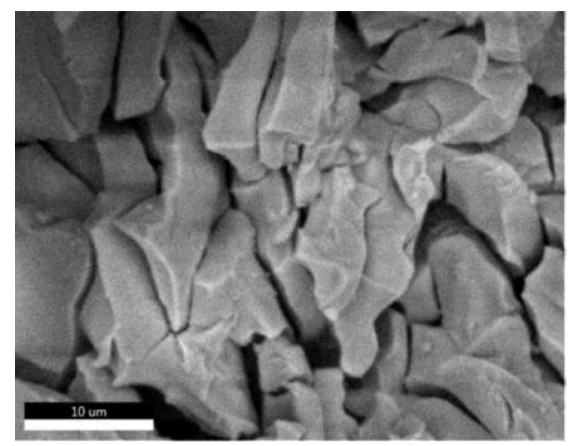

(a)

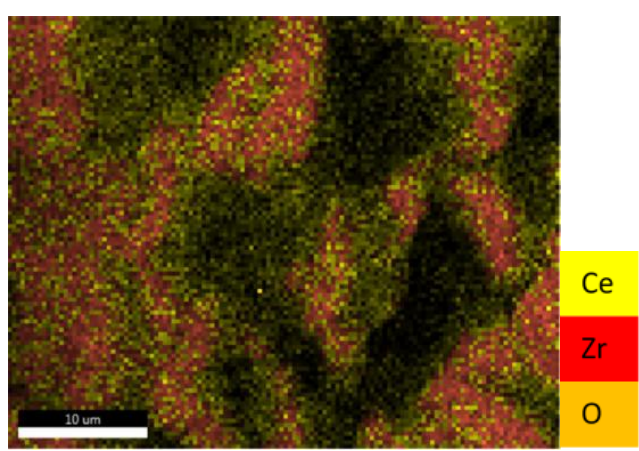

(b)

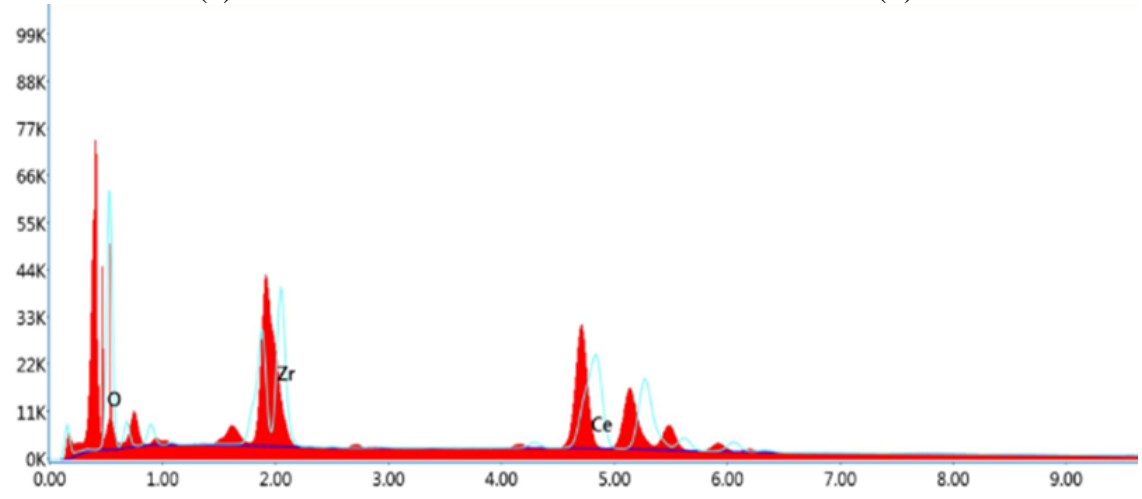

(c)

Figure 3 Pattern of SEM EDX for synthesized particles of cerium-zirconium oxides using ethylene glycol/water $(70: 30 \mathrm{v} / \mathrm{v})$ at a constant temperature of $150^{\circ} \mathrm{C}$ and synthesis time of $2 \mathrm{~h}$ : (a) SEM image of particles observed by EDX; (b) EDX mapping of particles; (c) EDX chromatogram of particles

The results indicate that atoms of oxygen, zirconium and cerium constructed the synthesized particles, with compositions of $22.14 \mathrm{wt} \%, 25.25 \mathrm{wt} \%$ and $52.61 \mathrm{wt} \%$, respectively. They also demonstrate that cerium-zirconium oxides composites were fabricated, with cerium attached to the entire surface of the zirconium oxide. The results agree those of with our previous work (Machmudah et al., 2016), that continuous hydrothermal synthesis produces a composite of cerium-zirconium oxides.

The crystal structure of the synthesized particles was observed by XRD. In general, the structures of cerium oxide and zirconium oxide were monoclinic and cubic respectively (Kusrini et al., 2009; Kusrini et al., 2010). Figure 4 shows the XRD patterns for the synthesized ceriumzirconium oxide particles with various solvents and at a constant pressure of 5 bar. All the synthesized particles for all the solvents exhibited a crystal structure. The crystal particle generation was created by the existence of organic solvent in the water solution (Machmudah et al., 2018). The composite of cerium-zirconium oxides $\left(\mathrm{Ce}_{0.18} \mathrm{Zr}_{0.19} \mathrm{O}_{2}\right)$ was confirmed at $2 \theta=$ $28.25^{\circ}, 34.20^{\circ}, 49.30^{\circ}$, and $57.52^{\circ}$ of diffraction lines. It can be seen in Figure 4 that the synthesized cerium-zirconium oxide particles had diffraction patterns deployed identically to 
establish a solid homogeneous solution. Moreover, the crystallinity of the synthesized particles was improved by the existence of chemicals such as organic solvent in the hydrothermal treatment at the same temperature. Hence, as depicted in Figure 4, the present of ethanol and ethylene glycol in the water solvent led to higher and clearer peak intensities. On the contrary, pure water solvent produced lower peak intensities. It seems that incomplete particle formation reaction occurred in the hydrothermal synthesis (Santolalla et al., 2013). In addition, the existence of chemicals as organic solvents in the hydrothermal treatment slightly enhanced the crystal diameter. This was determined from the peak broadening using Equation 3, namely Scherrer's equation:

$$
\mathrm{D}=\frac{K \lambda}{\beta \cos \theta}
$$

where $\mathrm{D}$ is the average crystal diameter $(\mathrm{nm}) ; K$ is the correction factor for counting the particle shapes with a value of $0.9 ; \lambda$ is the wavelength of the $\mathrm{X}$-ray $(0.154059 \mathrm{~nm})$; and $\beta$ and $\theta$ are the full-width at half-maximum (FWHM, in radians) intensity of a determined peak and the angle of diffraction respectively (Machmudah et al., 2016). Based on the calculation, the crystal diameters for the synthesized cerium-zirconium oxide particles using water, ethanol/water, and ethylene glycol/water solvents were $3.51 \mathrm{~nm}, 4.28 \mathrm{~nm}$ and $4.29 \mathrm{~nm}$, respectively.

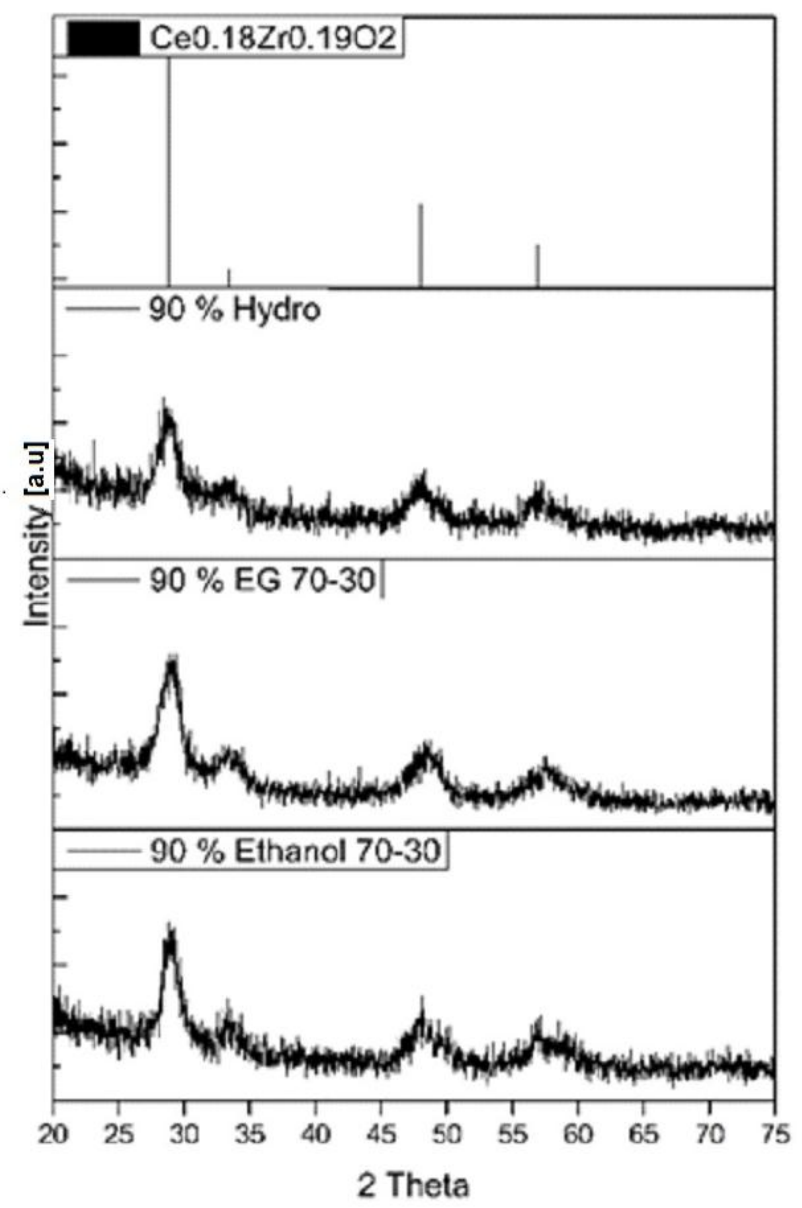

Figure 4 XRD pattern for synthesized particles of cerium-zirconium oxides at 5 bar and with various solvents

In order to confirm the production of cerium-zirconium oxide composite, synthesized particles were analyzed using FT-IR to observe the functional group of the Ce-O-Zr bonds. As shown in Figure $5 \mathrm{a}$, zirconium oxide has a band at $500-740 \mathrm{~cm}^{-1}$ corresponding to $\mathrm{Zr}-\mathrm{O}$, while cerium oxide 
has a band of $\mathrm{Ce}-\mathrm{O}$ at $600-750 \mathrm{~cm}^{-1}$ (Chelliah et al., 2012). In the cerium-zirconium oxide composite, the $\mathrm{Ce}-\mathrm{O}$ and $\mathrm{Zr}-\mathrm{O}$ bands disappeared, resulting in the smooth FT-IR spectra (Figure $5 b)$.

\subsection{Cerium-zirconium Oxide Particles for the Catalyst of Rapeseed Wood Delignification}

The delignification process was conducted by hydrothermal treatment at $150^{\circ} \mathrm{C}$ with and without cerium-zirconium oxide particles synthesized using various solvents. In this work, rapeseed wood was used as the biomass model compound for the delignification process. The lignin content in the initial rapeseed wood and the solid residue of the delignification process were determined to measure the percentage removal of lignin from the biomass. Table 2 shows the lignin removal of delignified rapeseed wood in the hydrothermal treatment with and without the cerium-zirconium oxide catalyst. The presence of the catalyst dramatically increased the percentage lignin removal. Cerium-zirconium oxides can beneficially increase the linkage fission between biopolymers and accelerate the deconstruction of lignin-carbohydrate complexes via the reducing property of carbohydrates. By increasing the pressure of the catalyst synthesis, the percentage lignin removal slightly increased. The increasing pressure on the catalyst synthesis might improve the formation of porous particles (Machmudah et al., 2016), and result in an increased oxidation reaction to decompose lignin from the rapeseed wood. The presence of the cerium-zirconium oxide catalyst formed by solvothermal synthesis using ethanol-water at 5 bar was able to remove lignin up to $97.58 \%$. It is evidenced that the presence of the cerium-zirconium catalyst effectively assisted the break-up and separation of lignin from the wood biomass.

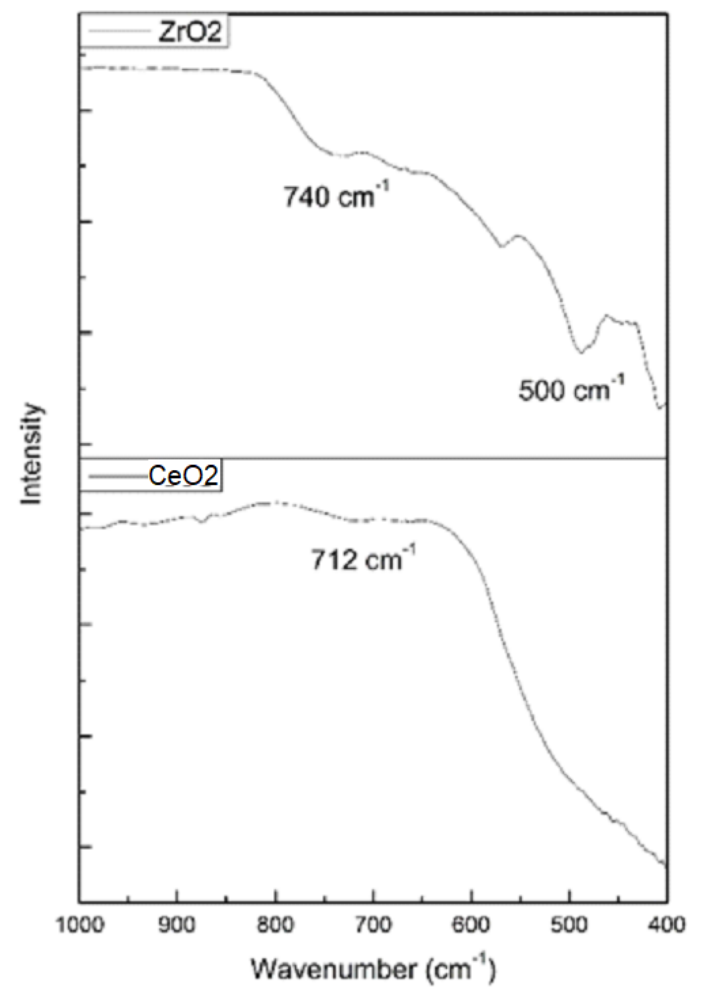

(a)

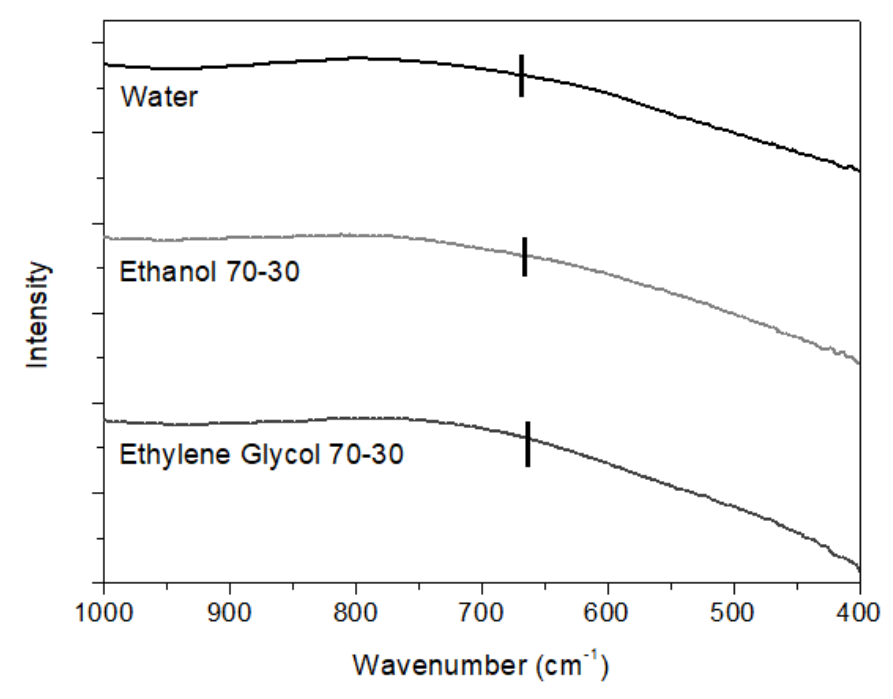

(b)

Figure 5 FTIR pattern of (a) zirconium oxide and cerium oxide; (b) cerium-zirconium oxide composite 
Table 2 Lignin removal in rapeseed wood delignification

\begin{tabular}{lcc}
\hline \multicolumn{1}{c}{ Species } & \% Lignin & \% Lignin Removal \\
\hline Initial rapeseed wood & 10.75 & - \\
Solid residue - no catalyst, 5 bar & 10.20 & 5.11 \\
Solid residue - catalyst water, 3 bar & 3.99 & 62.88 \\
Solid residue - catalyst water, 5 bar & 2.39 & 77.77 \\
Solid residue - catalyst Ethanol-water, 3 bar & 3.45 & 67.91 \\
Solid residue - catalyst Ethanol-water, 5 bar & 0.26 & 97.58 \\
Solid residue - catalyst EG-water, 3 bar & 3.31 & 69.21 \\
Solid residue - catalyst EG-water, 5 bar & 2.12 & 80.28 \\
\hline
\end{tabular}

In order to confirm the removal of lignin from the rapeseed wood, the solid residue from the delignification process was analyzed using FT-IR, and compared with the wood before the delignification process. The FT-IR spectra are shown in Figure 6. As a plant biomass, rapeseed wood mainly consists of lignin, hemicellulose and cellulose. Lignin is mostly composed of ketone, esters, alkene, aromatics and alcohol, with distinct oxygen comprising functional groups detected. In essence, the FT-IR spectra of rapeseed wood and its solid residues are similar, and vary only in the intensity of some of the peaks. It can be seen from Figure 6 that the compositions of their functional groups were not altered after the delignification process. Absorbance intensity of hydrogen bonded $\mathrm{O}-\mathrm{H}$ stretching $\left(3346 \mathrm{~cm}^{-1}\right)$ could be found in each spectrum with different strong intensities. Typical lignin spectra contain bands of aromatic ring vibrations at around 1600, 1512 and $1421 \mathrm{~cm}^{-1}$ : the band at $1167 \mathrm{~cm}^{-1}$ is defined as $\mathrm{C}=\mathrm{O}$ in the connected structure; the band at $833 \mathrm{~cm}^{-1}$ corresponds to $\mathrm{C}-\mathrm{H}$ in all location of the p-hydroxyphenyl units; the bands at 1031 and $918 \mathrm{~cm}^{-1}$ are assigned to guaiacyl units; and those at 1329 and $1124 \mathrm{~cm}^{-1}$ correspond to syringyl units. The FT-IR spectra of the rapeseed wood solid residue after delignification exhibited a decreasing absorbance intensity of the peaks, including in the lignin, compared with the original wood.

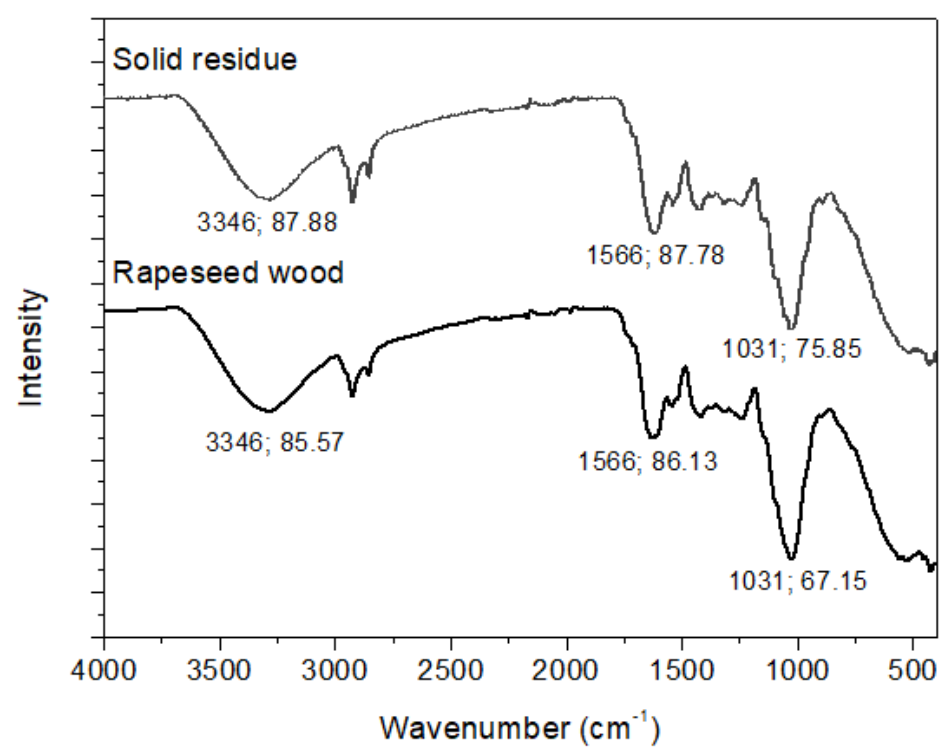

Figure 6 FTIR pattern of rapeseed wood and solid residue delignification process

\section{CONCLUSION}

Cerium-zirconium oxide particles were successfully synthesized with hydrothermal and solvothermal treatment at $150^{\circ} \mathrm{C}$. Solvent significantly influenced the morphology and crystallinity of the particles. The synthesized particles have an XRD pattern similar to the 
composite cerium-zirconium oxides of $\mathrm{Ce}_{0.18} \mathrm{Zr}_{0.19} \mathrm{O}_{2}$. As a catalyst, cerium-zirconium oxides were applied in the delignification process. The addition of cerium-zirconium oxide particles in the hydrothermal delignification process resulted in an increase in lignin removal from the rapeseed wood, from $5.11 \%$ without catalyst to $97.58 \%$ using the cerium-zirconium oxide catalyst. This indicates that ceria-zirconium oxides are effective in the hydrothermal delignification process and may reduce the use of chemical compounds for the pre-treatment of wood biomass in bio-refinery applications.

\section{ACKNOWLEDGEMENT}

The authors acknowledge funding from the Directorate General of Research and Development Strengthening, Ministry of Research, Technology, and Higher Education of the Republic of Indonesia through a PDUPT research grant (contract nos. 616/PKS/ITS/2017 and 925/PKS/ITS/2018).

\section{REFERENCES}

Aneggi, E., Cabbai, V., Trovarelli, A., Goi, D., 2012. Potential of Ceria-based Catalysts for the Oxidation of Landfill Leachate by Heterogeneous Fenton Process. International Journal of Photoenergy, Volume 2012, Article ID 694721, p. 8

Chelliah, M., Rayappan, J.B.B., Krishnan, U.M., 2012. Synthesis and Characterization of Cerium Oxide Nanoparticles by Hydroxide Mediated Approach. Journal of Applied Sciences, Volume 12(16), pp. 1734-1737

Dhall, A., Self, W., 2018. Cerium Oxide Nanoparticles: A Brief Review of their Synthesis Methods and Biomedical Applications. Antioxidants, Volume 7(8), pp. 1-13

Gil-Calvo, M., Jimenez-Gonzalez, C., De Rivas, B., Gutierrez-Ortiz, J., Lopez-Fonseca, R., 2017. Hydrogen Production by Reforming of Methane over $\mathrm{NiAl}_{2} \mathrm{O}_{4} / \mathrm{Ce}_{\mathrm{x}} \mathrm{Zr}_{1-\mathrm{x}} \mathrm{O}_{2}$ Catalysts. Chemical Engineering Transactions, Volume 57, pp. 901-906

Kanie, K., Seino, Y., Matsubara, M., Nakaya, M., Muramatsu, A., 2014. Hydrothermal Synthesis of $\mathrm{BaZrO}_{3}$ Fine Particles Controlled in Size and Shape and Fluorescence Behavior by Europium Doping. New Journal of Chemistry, Volume 38(8), pp. 3548-3555

Kusrini, E., Saleh, M.I., Lecomte, C., 2009. Coordination of Ce(III) and Nd(III) with Pentaethylene Glycol in The Presence of Picrate Anion: Spectroscopic and X-ray Structural Studies. Spectrochimica Acta Part A: Molecular and Biomolecular Spectroscopy, Volume 74(1), pp. 120-126

Kusrini, E., Saleh, M.I., Adnan, R., Fun, H-K., Yamin, B.M., 2010. Triclinic Structural Isomer of Cerium(III)-picrate Complexes with Triethylene Glycol. Journal of Coordination Chemistry, Volume 63(3), pp. 484-497

Kusrini, E., Utami, C.S., Usman, A., Nasruddin., Tito, K.A., 2018. $\mathrm{CO}_{2}$ Capture using Graphite Waste Composites and Ceria. International Journal of Technology, Volume 9(2), pp. 287296

Kwon, K., Lee, K.H., Jin, S., You, D.J., Pak, C., 2011. Ceria-promoted Oxygen Reduction Reaction in Pd-based Electrocatalysts. Electrochemistry Communications, Volume 13(10), pp. 1067-1069

Lundberg, M., Skarman, B., Cesar, F., Wallenberg, L.R., 2002. Mesoporous Thin Films of Highsurface-area Crystalline Cerium Dioxide. Microporous Mesoporous Materials, Volume 54(1-2), pp. 97-103

Machmudah, S., Prastuti, O.P., Widiyastuti, Winardi, S., Wahyudiono, Kanda, H., Goto, M., 2016. Macroporous Zirconia Particles Prepared by Subcritical Water in Batch and Flow Processes. Research on Chemical Intermediates, Volume 42, pp. 5367-5385 
Machmudah, S., Widiyastuti, Winardi, S., Wahyudiono, Kanda, H., Goto, M., 2018. Synthesis of Ceria Zirconia Oxides using Solvothermal Treatment. MATEC Web of Conferences, Volume 156,05014

Palma, V., Ruocco, C., Ricca, A., 2016. Low-Temperature Steam Reforming of Raw Bio-Ethanol Over Ceria-Zirconia Supported Catalysts. Chemical Engineering Transactions, Volume 52, pp. 193-198

Park, J., Shin, H., Yoo, S., Zoppe, J.O., Park, S., 2015. Delignification of Lignocellulosic Biomass and Its Effect on Subsequent Enzymatic Hydrolysis. Bioresources, Volume 10(2), pp. 2732-2743

Reddy, B.M., Bharali, P., Saikia, P., Khan, A., Loridan, S., Muhler, M., Grünert, W., 2007. Hafnium Doped Ceria Nanocomposite Oxide as a Novel Redox Additive for Three-way Catalysts. The Journal of Physical Chemistry C, Volume 111(5), pp. 1878-1881

Rumruangwong M., Wongkasemjit S., 2006. Synthesis of Ceria-zirconia Mixed Oxide from Cerium and Zirconium Glycolates via Sol-gel Process and Its Reduction Property. Applied Organometallic Chemistry, Volume 20(10), pp. 615-625

Santolalla, C., Chavez-Esquivel, G., de los Reyes-Heredia, J.A., Alvarez-Ramirez, J., 2013. Fractal Correlation Analysis of X-rayDiffraction Patterns with Broad Background. Industrial \& Engineering Chemistry Research, Volume 52(24), pp. 8346-8353

Suda, A., Sobukawa, H., Suzuki, T., Kandori, T., Ukyo, Y., Sugiura, M., 2001. Effect of Ordered Arrangement of $\mathrm{Ce}$ and $\mathrm{Zr}$ Ions on Oxygen Storage Capacity of Ceria-Zirconia Solid Solution. Journal of the Ceramic Society of Japan, Volume 112(1311), pp. 586-589

Yucai, H., 2006. Hydrothermal Synthesis of Nano Ce-Zr-Y Oxide Solid Solution for Automotive Three-way Catalyst. Journal of the American Ceramic Society, Volume 89, pp. 2949-2951

Zhou, G., Gorte, R.J., 2008. Thermodynamic Investigation of the Redox Properties for Ceria-Hafnia, Ceria-Terbia, and Ceria-Praseodymia Solid Solutions. The Journal of Physical Chemistry B, Volume 112, pp. 9869-9875 